\title{
ESTIMATIVA DO USO DE ÁGUA PARA FINS DE PROJETOS DE IRRIGAÇÃO, EM FUNÇÃO DA EVAPORAÇÃO DE TANQUE, EM RIBEIRÃO PRETO ${ }^{(1)}$
}

\footnotetext{
FLÂVIO BUSSMEYER ARRUDA (2), Seção de Irrigaçāo e Drenagem, Instituto Agronômico, $\epsilon$ LUIS FERNANDO SIMARDI BARROSO (3), Universidade Estadual dE Campinas.
}

\section{RESUMO}

Neste trabalho é apresentada uma análise dos resultados de 14 anos de evaporação do tanque enterrado IA-58, para fins de recomendação da necessidade de água em projetos de irrigação. As medições foram feitas no posto meteorológico da Estação Experimental de Ribeirão Preto, São Paulo. Os dados foram agrupados em. séries mensais, as quais apresentaram distribuiçăo normal e pequena assimetria. Todas as séries apresentaram valores significativos para curtose, mas os meses de abril, maio e junho mostraram forte distribuição leptocúrtica, com acúmulo de freqüência em torno da média. São apresentadas as freqüências mensais de ocorrência da evaporação diária, bem como a comparação entre o nivel de probabilidade $75 \%$ de ocorrência de evaporação (recomendado pela FAO) e o nivel de 50\% (comumente usado). Diferenças em até 35\%, durante a estação chuvosa, podem ocorrer entre os dois critérios de escolha de evaporação, podendo resultar em um sistema de irrigação subdimensionado.

(1) Os autores agradecem as sugestōes da pesquisadora Violeta Nagai. Recebido para publicação a 12 de agosto de 1983.

(2) Bolsista do CNPq.

(3) Bolsista do CNPq, pós-građuando no Departamento de Engenharia Agrícola. 


\section{INTRODUÇÃO}

O uso da evaporação de uma superficie livre de água, como critério para determinação do consumo máximo de água pelas culturas, tem sido amplamente aplicado em projetos de irrigação ou recomendações de manejo de água. Essas evaporações são obtidas de tarques instalados em postos meteorológicos, sob condiçōes padronizadas. A determinação da quantidade de água utilizada pela cultura é feita corrigindo a evaporação de tanque por um coeficiente de cultura determinado experimentalmente.

O valor da evaporação, que deve ser estabelecido criteriosamente, pois é nele que se inicia o dimensionamento do sistema de irrigação, em geral não é facilmente disponível, e quando uma série de resultados é compilada, é apresentada na forma de média mensal.

A apresentação da média mensal da evaporação posisivelmente tenha valor reduzido para fins de dimensionamento de sistemas de irrigação, em condiçōes de clima subtropical, pois inclui em seu cáiculo as baixas evaporações ocorridas nos dias de chuva. As irrigações são realizadas em épocas de escassez de chuva e de evaporação mais elevada: o emprego da média mensal, portanto, subestima a demanda de água pela cultura, e o sistema será subdimensionado para o perícdo de máxima intensidade de uso.

As alternativas para resolver o problema seriam ou utilizar da evaporação de períodos consecutivos, sem ou com baixa precipitação, ou considerar apenas os maiores valores de evaporação. No primeiro caso, além de muito trabalhoso, os períodos consecutivos variam com os intervalos de irrigação e com a cultura. No segundo, é evidente que apenas um valor máximo de evaporação ocorrido no mês não serve como base para o projeto, mesmo porque, do ponto de vista fisiológico, a planta é capaz de superar curto periodo de seca sem danos à produção e, em geral, valores extremos podem ter erros de mediçāo que não expressam a realidade.

Uma possibilidade de melhor representar uma série de valores de evaporação, e de seu melhor uso em irrigação está em epresentá-ios na sua freqüência de ocorrência, conforme sugerido por PRUTTT et alii (4).

\section{MATERIAL E MẼTODOS}

Este trabalho consistiu na análise dos resultados de evaporação do tanque IA-58, instalado no posto meteorológico, sob condições de gramado na Estação Experimental de Ribeirão Preto do instituto Agronômico, no período de 1962 a 1975 . Esse tanque, do tipo enterrado, foi descrito por TOSELLO (5).

Os dados foram agrupados em base mensal, e calculadas as freqüências de ocorrência dos valores em classes de $0,5 \mathrm{~mm} \cdot$ dia $^{-1}$ de intervalo. 
A seguir, foram determinadas as evaporaçōes correspondentes às freqüências acumuladas de $95 \%, 90 \%, 80 \%, 75 \%, 50 \%, 25 \%, 10 \%$ e $5 \%$, e calculadas as estatísticas referentes às curvas de distribuição das evaporações mensais.

\section{RESULTADOS E DISCUSSÃO}

No quadro 1 encontram-se os resultados obtidos das estatísticas de distribuição das freqüências de evaporação mensal, cuja variação de 2,2 a 4,2mm.dia ${ }^{-1}$ nas médias mensais, mostra a pequena amplitude de variação anual. Por esse critério das médias mensais, os valores $3,0 \mathrm{~mm}$. dia ${ }^{-1}$ no inverno e $4,0 \mathrm{~mm} \cdot \mathrm{dia}^{-1}$ no verão são aceitáveis como representativos da evaporação anual, comumente usados em projetos å irrigação no Estado de São Paulo.

Os valores do coeficiente de assimetria apresentaram-se muito próximos de zero, fato esse bastante desejado, pois sugere simetria da curva em torno do valor de tendência central. Há, no entanto, indícios de acentuada curtose; abril, maio e junho mostraram desvios significativos a niveis superiores a $1 \%$, pelo teste de curtose (3). Nesses casos, há um acúmulo de freqüência em torno da média (2). Para a recomendação de irrigação, a distribuição leptocúrtica (curtose elevada) não prejudica a escolha do valor de evaporação a ser utilizado, desde que ele seja próximo da média e esteja contido numa classe cuja freqüência seja elevada.

Uma análise dos resultados obtidos nos meses de abril a junho mostrou que há uma drástica diminuição das freqüências uma ou duas classes de valores acima da média, conforme mostra ') quadro 2.

QUADRO 1. Evaporação média mensal, desvio padrão e coeficientes de assimetria e curtose, em 1962-1975, na Estação Experimental de Ribeirã̃o Preto

\begin{tabular}{lcccr} 
Mês & Média & $\begin{array}{c}\text { Desvio- } \\
\text {-padrão }\end{array}$ & Assimetria & Curtose \\
\hline Janeiro & mm/dia & & & \\
Fevereiro & 3,9 & 2,10 & $1,17^{*}$ & $4,24^{*}$ \\
Março & 3,5 & 1,85 & 0.13 & $0,87^{*}$ \\
Abril & 3,4 & 1,41 & $-0,01$ & $3,34^{*}$ \\
Maio & 3,3 & 1,26 & $3,42^{*}$ & $8,42^{*}$ \\
Junho & 2,7 & 1,04 & $1,42^{*}$ & $10,40^{*}$ \\
Julho & 2,2 & 0,94 & $1,80^{*}$ & $2,15^{*}$ \\
Agosto & 2,2 & 1,00 & $-0,20$ & $2,79^{*}$ \\
Setembro & 3,4 & 1,05 & $0,67^{*}$ & $3,79^{*}$ \\
Outubro & $\mathbf{4 , 0}$ & 1,64 & $0,34^{*}$ & $0,88^{*}$ \\
Novembro & 3,8 & 1,94 & $0,99^{*}$ & $1,80^{*}$ \\
Dezembro & $\mathbf{4 , 2}$ & 1,80 & 0,17 & $0,48^{*}$ \\
\hline
\end{tabular}

* Significativo ao nivel de $5 \%$. 
QUADRO 2. Frequiência relativa de ocorrência, por classe, de evaporação do tanque IA-58, em 1962-1975, na Estação Experimental de Ribeirão Preto

\begin{tabular}{|c|c|c|c|}
\hline \multirow{2}{*}{$\begin{array}{c}\text { Classe } \\
\text { de } \\
\text { evaporação }\end{array}$} & \multicolumn{3}{|c|}{ Freqüências } \\
\hline & Abril & Maio & Junho \\
\hline $\mathrm{mm} /$ dia & $\%$ & $\%$ & $\%$ \\
\hline $0-0,5$ & 1,8 & 1,7 & 1,5 \\
\hline $0,5-1,0$ & 0,0 & 1,2 & 3,1 \\
\hline $1,0-1,5$ & 2,3 & 5,0 & 10,0 \\
\hline $1,5-2,0$ & 2,3 & 15,1 & 23,6 \\
\hline $2,0-2,5$ & 11,8 & 14,9 & 27,9 (1) \\
\hline $2,5-3,0$ & 21,3 & $26,1^{(1)}$ & 17,1 \\
\hline $3,0-3,5$ & $22,4(1)$ & 18,6 & 8,7 \\
\hline $3,5-4,0$ & 18,5 & 9,9 & 3,6 \\
\hline $4,0-4,5$ & 9,8 & 4,5 & 2,8 \\
\hline $4,5-5,0$ & 5,1 & 1,0 & 0,0 \\
\hline $5,0-5,5$ & 1,8 & 0,7 & 0,5 \\
\hline $5,5-6,0$ & 0,5 & 0,2 & 0,5 \\
\hline $6,0-6,5$ & 1,0 & 0,2 & 0,2 \\
\hline $6,5-7,0$ & 0,5 & 0,0 & 0,0 \\
\hline $7,0-7,5$ & 0,0 & 0,2 & 0,0 \\
\hline $7,5-8,0$ & 0,3 & 0,0 & 0,0 \\
\hline $8,0-8,5$ & 0,0 & 0,2 & 0,0 \\
\hline $8,5-9,0$ & 0,0 & 0,0 & 0,0 \\
\hline $9,0-9,5$ & 0,0 & 0,0 & 0,0 \\
\hline $9,5-10,0$ & 0,3 & 0,0 & 0,2 \\
\hline $10,0-10,5$ & 0,0 & 0,2 & \\
\hline $10,5-11,0$ & 0,0 & & \\
\hline $11,0>$ & 0,3 & & \\
\hline
\end{tabular}

(1) Classes de evaporação em que a média está incluída.

Os resultados de evaporação calculados para os vários niveis de freqüência são mostrados na figura 1. Um nível de $100 \%$ engloba todos os valores de evaporação ocorridos no período considerado. O nível de 95\% elimina 5\% das evaporações extremas, que podem ser resultado de erros, e esse nível representa os valores máximos confiáveis de evaporação. O nível de $50 \%$ representa as evaporações mensais médias (Quadro 1). Conforme comentado, a média mensal não apresenta muita variação anual, mas as evaporações nos niveis de ocorrêncic mais elevada mostram variaçōes com as estaçōes, como seria de esperar, com base em experiência no campo.

Para uso em irrigação, a escolha da evaporação representativa do mês deve ser feita de acordo com o grau de segurança do manejo da água e com a importância do projeto. O critério recomendado pela FAO (in 1) é que esse nível de probabilidade seja $75-80 \%$ ou maior. 


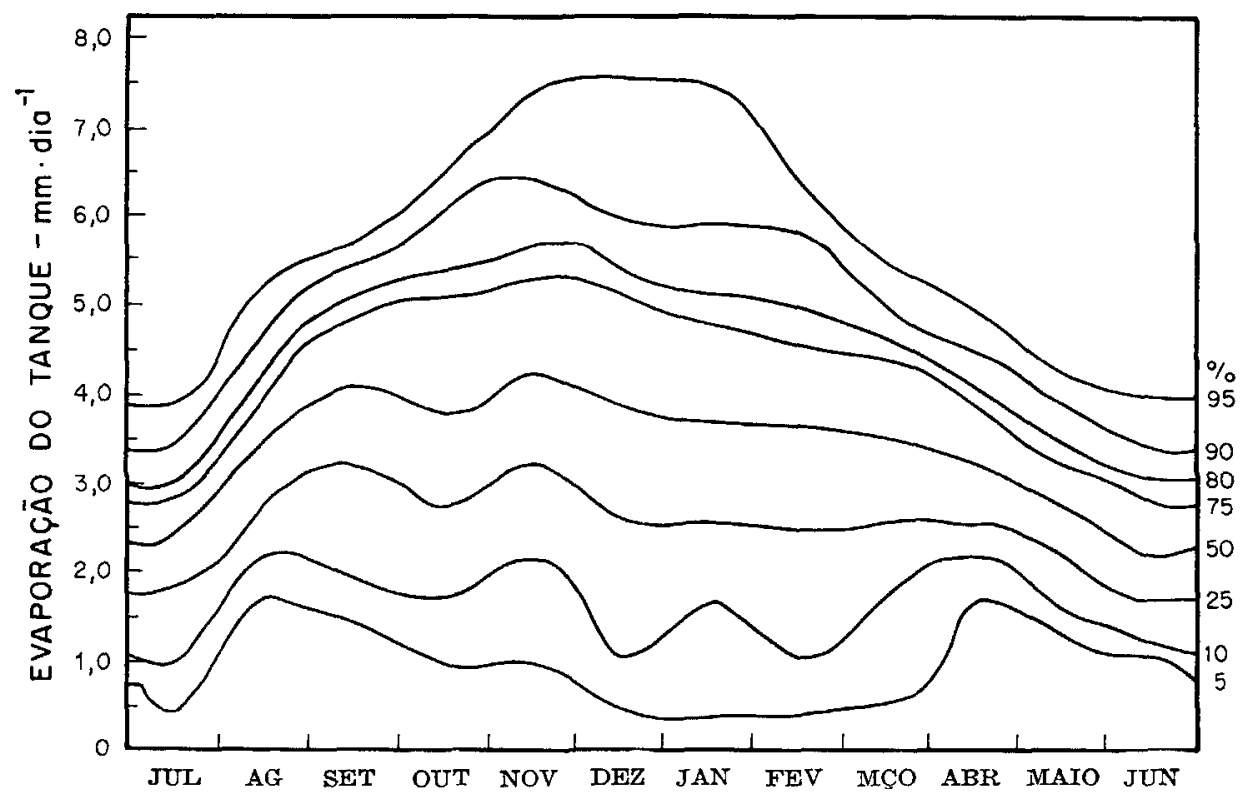

FIGURA 1. Curvas de evaporação do tanque IA-58 para várias frequiências de ocorrência mensal. Período de 1962 a 1975, na Estação Experimental de Ribeirão Preto.

O quadro 3 apresenta a evaporação do tanque IA-58, ao adotado nível de $75 \%$, para Ribeirão Preto. Comparando seus valores com as evaporações médias (Quadro 1), constatam-se diferenças em até 35\% durante os meses da estação chuvosa.

QUADRO 3. Evaporação mensal em $1962-1975$ em Ribeirão Preto, no nivel de $75 \%$ de ocorrência

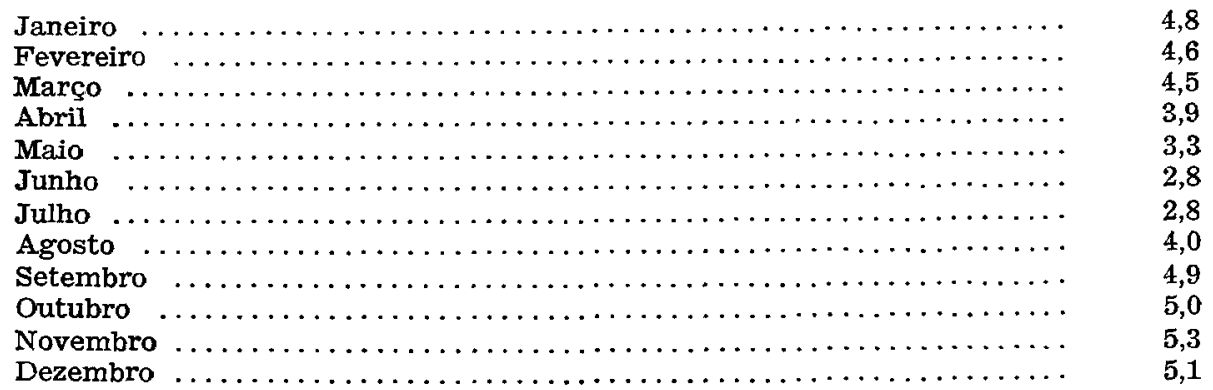


Pesquisas têm mostrado que não existem grandes diferenças entre os tipos de tanque, mas em geral os enterrados, como o IA-58, apresentam valores mais baixos que o Classe $A$, porém mais altas correlações com a evapotranspiração real. Estudos da ocorrência de evaporação de superfície livre no Estado de São Paulo e sua distribuição vêm sendo conduzidos, visando a maior precisão no planejamento e projeto das irrigações.

\section{SUMMARY}

\section{USE OF PAN EVAPORATION FOR ESTIMATING MAXIMUM WATER USE FOR IRRIGATION DESIGN IN RIBEIRÃO PRETO, BRAZIL}

Fourteen years of IA-58 sunken pan evaporation data were analysed for predicting irrigation needs. The measurements were carried out in Ribeirão Preto, State of São Paulo. The data were grouped in 12 monthly series which followed the normal distribution with small skewness. All series had significant values for kurtosis, but April, May and June presented strong leptokurtic distributions, i.e., there was a piling up of scores in the center of the distribution. For each month the frequency distribution of mean daily evaporation as well as the comparison between the $75 \%$ level of probability of evaporation (recommended by FAO) and the $50 \%$ level (commonly used), are presented. Differences of up to $35 \%$, during the rainy season, can occur between the two criteria and might result in improper design of irrigation system.

\section{REFER̂ANCIAS BIBLIOGRĀFICAS}

1. DOORENBOS, J. \& PRUTTT, W.O. Crop water requirements, Roma, FAO, 1977. 156p. (EAO Irrig. and Drain. Paper, 24- rev.)

2. HABER, A. \& RUNYON, R.P. General statistics. California, Addison-Wesley Publishing Co., Inc., 1973. 401p.

3. PEARSON, E.S. \& HARTLEY, H.O. Biometrika tables for statisticians. Cambridge, The University Press, 1954. v.1.

4. PRUTTT, W.O.; OETTIGEN, S. Von; MORGAN, D.L. Central California evapotranspiration frequencies. Journal of Irrigation and Drainage Division, ASCE, 98 (IR2):177-184, 1972.

5. TOSELlo, R.N. Novo tipo de evaporímetro terrestre. Bragantia, Campinas, 19:731-751, 1960. 